\section{An Unusual Case of Acute Kidney Injury}

Farah A. Mansour, M.D., Boutros N. El Haddad, M.D., Roy A. Raad, M.D., Najat I. Joubran, M.D., Rami Chemali, M.D.

Balamand University, St. George Hospital University Medical Center, Beirut, Lebanon

Received Nov. 2, 2020; Accepted for publication Dec. 21, 2020; Published online March 19, 2021 https: doi.org 10.17161 lijm.voll414811

\section{INTRODUCTION}

Bladder catheter insertion is among the most common and routine urological procedures done not only for diagnostic but also for therapeutic purposes. ${ }^{1}$ In the majority of cases, it is considered a safe procedure with no major complications. Inadvertent placement of the bladder catheter into the ureter is rare with around 25 case reports published in the English literature. ${ }^{1-5}$ It results in various complications such as ureteric obstruction leading to hydronephrosis, acute kidney injury, ureteric injury, and even rupture. ${ }^{1}$

\section{CASE REPORT}

A 77-year-old Middle Eastern gentleman with a past medical history of hypertension, nephrolithiasis, and benign prostatic hyperplasia status post transurethral resection of the prostate presented with seven days history of left flank pain, fever, and chills. Initial investigations showed a creatinine of $1.36 \mathrm{mg} / \mathrm{dl}(\mathrm{nl}=0.4-1 \mathrm{mg} / \mathrm{dl})$, C-reactive protein $11.6 \mathrm{mg} /$ $\mathrm{dl}(\mathrm{nl}=0-0.5 \mathrm{mg} / \mathrm{dl})$, and white blood cell (WBC) count $8.8 \mathrm{~mm}^{3}(\mathrm{nl}=$ $4-10 \times 103 / \mathrm{mm}^{3}$ ), urinalysis showed trace protein, leukocyte esterase

$80 / \mathrm{mm}^{3}$, red blood cells $>150 / \mathrm{hpf}$, and numerous WBCs. Urine and blood cultures were taken.

A non-contrast computed tomography scan of the abdomen and pelvis showed a $9.5 \times 14 \times 25 \mathrm{~mm}$ calculus in the left renal pelvis in addition to left moderate hydronephrosis. The scan also noted mild left perinephric and proximal periureteric fat stranding with other multiple non-obstructing left renal calculi. The right kidney was normal in size with no evidence of hydronephrosis, mass, or calculi. The patient was diagnosed with obstructive pyelonephritis and he was started on ceftriaxone.

Ureteral pig tail stent insertion by cystouretheroscopy was not successful because the left ureteral orifice could not be identified. Percutaneous nephrolithotomy was performed and anterograde ureteral stent was inserted under general anesthesia. A 16 Fr urethral balloon catheter was placed before the start of the procedure. Postoperatively, lab results showed worsening kidney function with an increase in the serum creatinine from 1.36 to $2.9 \mathrm{mg} / \mathrm{dl}$ on post-operative day one and $4.7 \mathrm{mg} / \mathrm{dl}$ on post-operative day 2 .

A repeat non-contrast computed tomography (CT) scan of his abdomen and pelvis was performed showing the tip of the indwelling Foley catheter located within the right vesicoureteric junction, with new mild dilatation of the right ureter and right hydronephrosis, highly suggestive of obstruction of the distal ureter due to obstruction by the indwelling Foley catheter (Figure 1,2A). The CT scan showed the resolution of the left hydronephrosis. Subsequently, the indwelling Foley catheter was removed, and a repeat CT scan after 48 hours showed the resolution of the new right hydronephrosis (Figure 2B). Renal function improved with a decrease in creatinine level to baseline. The patient was discharged home after getting a full course of antibiotics.

\section{KANSAS JOURNAL of MEDICINE}

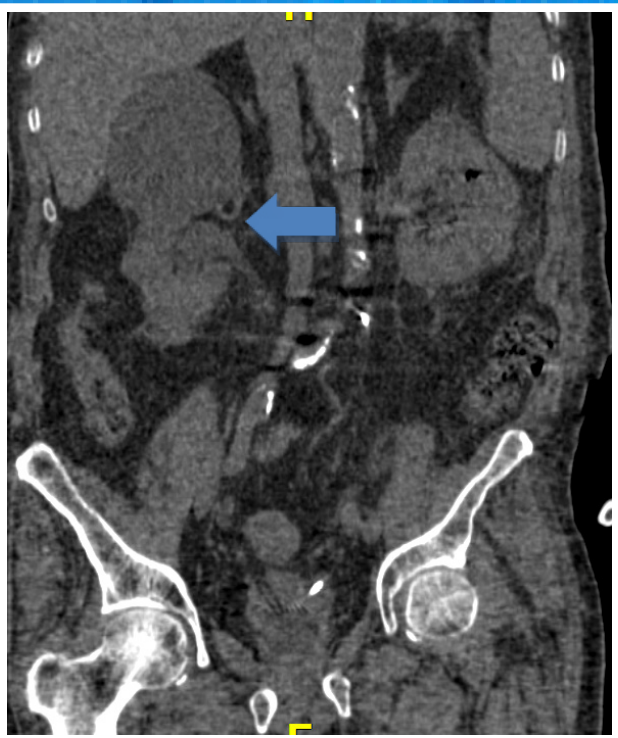

Figure 1. Coronal non-enhanced CT scan of the abdomen and pelvis shows Foley catheter terminating within the right ureterovesical junction and right hydronephrosis with associated right perinephric fat stranding.

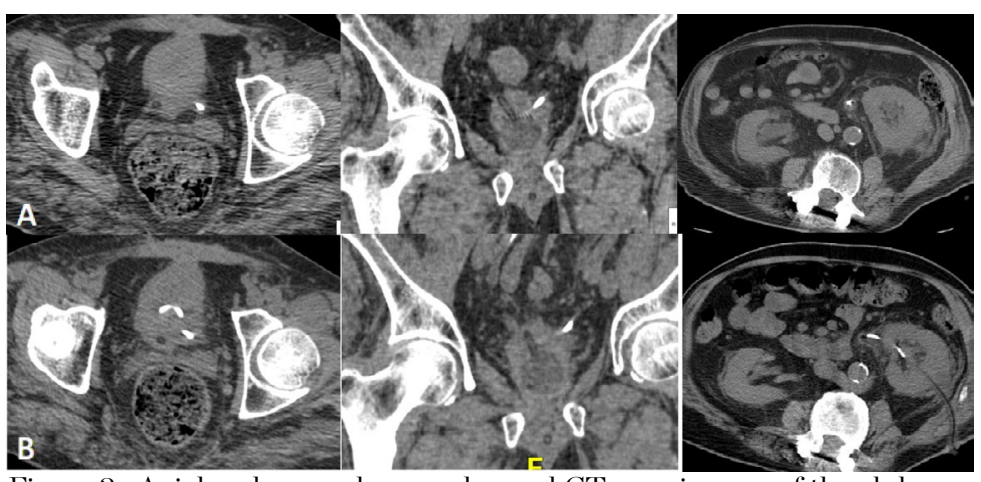

Figure 2. Axial and coronal non-enhanced CT scan images of the abdomen and pelvis demonstrates: (A) the Foley catheter terminating within the right ureterovesical junction and right hydronephrosis with associated right perinephric fat stranding; (B) non-enhanced CT scan images of the abdomen and pelvis obtained 2 days after retraction and adjustment of the position of the Foley catheter, now within the urinary bladder showing resolution of the right hydronephrosis associated right perinephric fat stranding. Note the presence of a left ureteral stent.

\section{DISCUSSION}

Insertion of a Foley catheter, despite being considered to be a safe procedure, can be associated with some complications that range from minor (bleeding, infection, or malfunction) to serious (perforation, obstruction, or hydronephrosis). ${ }^{6}$ Misplacement of Foley catheter into the ureter is rare with around 25 cases reported in the English literature..$^{1-5}$ Insertion of Foley tip or inflation of catheter balloon in the ureter may cause deleterious side effects such as ureteral obstruction, hydronephrosis, pyelonephritis, severe ureteral injury, and even rupture in severe cases. ${ }^{1}$

Catheterization of an empty bladder and chronic catheter use increase the risk of inadvertent insertion secondary to bladder contraction due to ensuing change in the anatomy between the bladder neck and ureteral orifice. ${ }^{1,7}$ Other reported risk factors include frequent catheterization, neurogenic bladder, spinal cord injury, and vesicoureteric reflux. ${ }^{1,8}$ Females are at higher risk due to shorter urethra with a

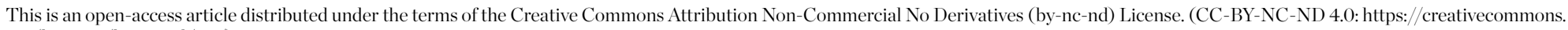
org/licenses/by-nc-nd/4.0/) 


\section{KANSAS JOURNAL of MEDICINE}

ACUTE KIDNEY INJURY

continued.

female to male ratio of $3: 1 .^{1,6}$

Patients can be asymptomatic but usually complain of flank pain, abdominal pain, or fever. ${ }^{1}$ For patients with impaired sensation, a catheter leak, or inability to inflate the balloon would be a clue for misplaced catheter. Incidental finding on imaging or during surgery also has been reported. ${ }^{9}$

The diagnosis usually is made by imaging studies including ultrasound, CT scan, intravenous urography, retrograde pyelography, or catheterography. ${ }^{1}$ Diagnosis also can be done by cystoscopy which could be therapeutic. Because of it is low incidence, it not recommended to perform routine diagnostic studies after Foley catheter insertion.

Contrary to most of patients described in the literature who had risk factors, our patient did not have any. This highlighted the fact that this complication should be considered even in the absence of known risk factors.

To prevent inadvertent placement, over insertion of the bladder catheter into the lumen should be avoided. After balloon inflation with no resistance, the catheter should be pulled back gently until the catheter balloon rests on the bladder neck. ${ }^{10}$ Other suggested measures include using short tip catheters and placement under ultrasound guidance. $^{1,10}$

Misplaced Foley catheter into the ureter without ureteral injury can be managed simply by conservative measures such as removing or replacing it. ${ }^{1}$ However, more pronounced ureteral injury might require nephrostomy tubes placement, stent placement, and even surgical repair in severe cases. ${ }^{3}$

Our patient did not complain of any symptoms. Misplaced Foley catheter was noted on CT scan of the abdomen and pelvis which was done as a diagnostic procedure for elevated creatinine and oliguria. He did not require any invasive or surgical procedure as the misplaced catheter was removed directly upon diagnosis with no complications.

\section{CONCLUSIONS}

Aberrant placement of urinary catheter into the ureter is a rare complication of bladder catheter insertion. Although uncommon, such complication increases morbidity and may lead to long term sequela. Care should be taken to avoid such a complication. Caretakers should keep a high index of suspicion in case of worsening kidney function, oliguria, or flank or abdominal pain that follow bladder catheter insertion and treatment should be initiated promptly in case of aberrant placement.

\section{REFERENCES}

${ }^{1}$ Luo R, Lee SL, Ng FC, Koh LT. Inadvertent placement of a urinary catheter into the ureter: A report of 3 cases and review of the literature. Asian J Urol 2016; 4(4):256-26l. PMID: 29387559.

${ }^{2}$ Persaud S, Al-Dabbagh M, Chalokia R, Datta S. An uncommon complication of a common procedure: Aberrant placement of a catheter into the ureter following suprapubic cystostomy. Int J Med Rev Case Rep 2018; 2(3):79-81.

3 Agarwal S, Goel S, Aeron R, Sankwar SN. Misplaced Foley catheter in ureter in a female with neurogenic bladder: A rare complication report. BMJ Case Rep 2018; bcr2018226144. PMID: 30121570.
4 Rajaian S, Murugavaithianathan P, Krishnamurthy K, Murugesan L. Retrograde pyelogram during intended cystogram: A rare complication of a common procedure. J Clin Imaging Sci 2018; 8:55. PMID: 30652058.

${ }^{5}$ Ishikawa T, Araki M, Hirata T, et al. A rare complication: Misdirection of an indwelling urethral catheter into the ureter. Acta Med Okayama 2014; 68(1):47-5l. PMID: 24553489.

${ }^{6}$ Pandey S, Sharma D, Garg G, Sankhwar S. Inadvertent inflation of Foley catheter balloon with contrast: An error that caused unnecessary apprehensions. BMJ Case Rep 2018; 2018: bcr2018225153. PMID: 29643144.

7 Mai ZF, Yang CH, Huang YC. Misdirection of an indwelling urethral catheter in the ureter. J Acute Med 2016; 6(2):52-54.

${ }^{8}$ Anderson BW, Greenlund AC. Ureteral cannulation as a complication of urethral catheterization. Korean J Urol 2014; 55(11):768-771. PMID: 25405021.

9 Singh NP, Eardley I. An uncommon complication of urethral catheterization. Br J Urol 1996; 77(2):316-317. PMID: 8800911.

10 Adeyemo B, Makovitch S, Foo D. A peculiar complication of suprapubic catheterization: Recurrent ureteral obstruction and hydronephrosis. J Spinal Cord Med 2013; 36(2):166-169. PMID: 23809534.

Keywords: acute kidney injury, urinary catheters, Foley catheterization, case report 